\title{
La aplicación de los géneros informativos e interpretativos en las tertulias políticas del Grupo Intereconomía
}

\author{
Marta Rico JEREZ \\ Universidad Camilo José Cela \\ martaricoj@gmail.com
}

Recibido: 20 de diciembre de 2013

Aceptado: 23 de junio de 2014

\begin{abstract}
Resumen
Este artículo es parte de los resultados obtenidos de una investigación realizada por la autora titulada "Intereconomía: De radio local especializada en economía y finanzas a grupo multimedia con la información política como eje vertebrador". Una de las conclusiones logradas en este trabajo fue que la simbiosis entre información y opinión ya no es solo característica de los medios informativos, sino que también se produce en los programas tradicionalmente llamados "de opinión", como son las tertulias. Por tanto, para realizar este estudio se utilizaron la metodología cualitativa y la metodología cuantitativa, ya que se hicieron una revisión de la literatura sobre el objeto de estudio y un análisis de contenido de las tertulias políticas del Grupo Intereconomía.
\end{abstract}

Palabras clave: Tertulias políticas, géneros informativos, géneros interpretativos, géneros de opinión, Grupo Intereconomía

\section{The application of informative and interpretive genres in political get togethers of the Intereconomía Group}

\begin{abstract}
This article is part of the results of research conducted by the author entitled "Intereconomía: From local radio specialized in economy and finances to multimedia group with political news as centre of its activity". One of the conclusions obtained in this work is that the symbiosis between opinion and information is not only a feature of news programs, it also happens in programs traditionally called "review". For example, the gatherings. Therefore, the qualitative methodology and the quantitative methodology were used, since a review of literature on the subject of study and a content analysis of the political gahterings of Intereconomia Group were made.
\end{abstract}

Keywords: Political get togethers, news genres, interpretive genres, review genres, Intereconomia Group

\section{Referencia normalizada}

RICO JEREZ, Marta (2014): "La aplicación de los géneros informativos e interpretativos en las tertulias políticas del Grupo Intereconomía". Estudios sobre el Mensaje Periodístico. Vol. 20, Núm. 2 (juliodiciembre), págs.: 873-884. Madrid, Servicio de Publicaciones de la Universidad Complutense

Sumario: 1. Introducción. 2. Metodología. 3. La opinión como elemento clave de los medios audiovisuales españoles. 4. Las tertulias como máximo exponente de la opinión en los medios audiovisuales. 5. Características básicas de las tertulias políticas del Grupo Intereconomía. 6. La aplicación de los géneros informativos e interpretativos en las tertulias políticas de Intereconomía; 6.1. Géneros audiovisuales radiofónicos; 6.2. Géneros audiovisuales televisivos; 6.3. Los géneros en las tertulias políticas del Grupo Intereconomía. 7. Conclusiones. 8. Referencias bibliográficas. 


\section{Introducción}

En los años 80 se produjo en España una concentración de los medios de comunicación y un aperturismo ideológico. Este último dio lugar a que la política se convirtiera en el tema principal, sobre todo, en la radio (García, 2006: 87-88) en la que proliferaron los debates y las tertulias. Al mismo tiempo la opinión fue adquiriendo cada vez mayor importancia, hasta el punto de que es que fácil encontrarla combinada con la información en los programas informativos, pues como dice el profesor Cebrián (2001: 180-200), se "mezcla intencionadamente la noticia con la opinión", ya que se trata de "un periodismo de combate: a favor de unas corrientes políticas y en contra de otras, e incluso, se diferencia dentro de cada corriente a las personas por estar a su favor o atacarla. Se eligen y valoran las noticias según una tendencia u otra". Por eso, el objetivo de esta investigación fue analizar si esta tendencia también tenía lugar en los programas de opinión, lo cual se hizo a través de las tertulias políticas del Grupo Intereconomía.

\section{Metodología}

La investigación aquí planteada se llevó a cabo en varias fases entre las que cabe destacar tanto la revisión de la literatura relacionada con el objeto estudio para compilar la información correspondiente al marco teórico como el análisis de contenido de tres programas de opinión del Grupo Intereconomía. De ahí que se haya utilizado tanto metodología cualitativa como metodología cuantitativa, pues de todos ellos se examinaron los temas tratados y los géneros aplicados. Estos últimos según la siguiente catalogación:

- Géneros informativos: noticia e informe.

- Géneros interpretativos: crónica, reportaje y documental.

- Géneros opinativos: entrevista, comentario, crítica, tertulia y debate.

- Géneros artísticos: docudrama y obra abierta.

Concretamente, se estudiaron setenta y cinco horas de las siguientes tertulias centradas en el contenido político:

a) La Espuela (se emitía de lunes a viernes en Radio Intereconomía):

- Período analizado: 27-04-2012 a 29-05-2012, lo que equivale a diecinueve días al no haberse analizados los festivos en Madrid y los fines de semana.

- Duración programa: una hora.

- Número horas analizadas: diecinueve.

b) El Gato al Agua (se emitía en Radio Intereconomía e Intereconomía Televisión):

- Período analizado: 27-04-2012 a 29-05-2012, lo que equivale a diecinueve días al no haberse analizados los festivos en Madrid y los fines de semana.

- Duración programa: dos horas.

- Número horas analizadas: treinta y ocho.

c) Más se perdió en Cuba (se emitía los sábados en Radio Intereconomía e Intereconomía Televisión).

- Período analizado: 28-04-02012 a 26-05-2012, lo que equivale a seis programas.

- Número horas analizadas: dieciocho. 


\section{La opinión como elemento clave de los medios audiovisuales españoles}

Según Santamaría \& Casals (2000: 45-91), "la opinión es un pensamiento comunicado, la idea sobre las cosas, sobre el mundo, que cada uno posee, transmite y comparte". Por tanto, "no debe confundirse la opinión totalmente subjetiva con el análisis riguroso y lógico de los hechos, de las declaraciones y situaciones. El análisis trata de explicar, la opinión aporta pensamiento y visión personal sobre lo ocurrido" (Cebrián, 2001: 180-200).

La opinión ha ido adquiriendo cada vez más importancia en los medios de comunicación hasta el punto de que, como dice el profesor Cebrián, se "mezcla intencionadamente la noticia con la opinión", ya que se trata de "un periodismo de combate: a favor de unas corrientes políticas y en contra de otras, e incluso, se diferencia dentro de cada corriente a las personas por estar a su favor o atacarla. Se eligen y valoran las noticias según una tendencia u otra". Esto no solo ocurre en la información de política nacional, sino que concierne a todos los contenidos informativos.

Además, "la opinión se ha convertido en un elemento clave en la radio española hasta desbancar en gran parte a los demás programas excepto los noticiarios y los magacines" (Cebrián, 2001: 180-200). Su fuerza ha llegado a ser tal que "se posicionan en torno a la línea pro o antigubernamental y a favor de un partido político o de otro. En algunos casos se plantean como si se tratara de la oposición política".

Con respecto a la televisión generalista, se debe comentar que el promotor de combinar la información con la opinión fue el periodista José María Carrascal, quien inició esta tendencia en sus informativos de Antena 3 en donde, con una entonación editorializante, presentaba las entradillas de las noticias plagadas de asientos y valoraciones personales (Mateos-Pérez, 2009). Su éxito propició que el resto de las televisiones utilizaran la misma fórmula.

A esta tendencia de introducir la opinión en las noticias, le siguió la puesta en marcha de programas de confrontación de ideas como los debates o las tertulias. Sin embargo, esta confrontación no suele tener lugar, debido a que se selecciona a los tertulianos en función de la ideología y de la línea editorial del medio de comunicación, por lo que "hay diversidad de voces, pero dentro de una tendencia homogénea de estar a favor o en contra de algo o de alguien" (Cebrián, 2001, 18-200).

Aparte de este inconveniente, tanto en la radio como en la televisión existe otro problema relacionado con el tratamiento de la opinión, pues como comenta el profesor Cebrián (2004: 88-90), "hay un deterioro creciente de la dialéctica argumental a favor del apasionamiento personal. No es discrepancia o choque de ideas, sino de opiniones sin base. La cuestión es concentrar la atención con algunos gritos y exabruptos. Se busca el entretenimiento y no la reflexión, la retención de ideas, el sopesamiento de las mismas y la obtención de argumentos y conclusiones personales".

\section{Las tertulias como máximo exponente de la opinión en los medios audiovisuales} "La primera definición de tertulia que se conoce es la de Cadalso: «cierto número de personas que concurren con frecuencia a una conversación»" (Santamaría \& Casals, 2000: 309 -310). De hecho, como dicen las mismas autoras, "durante algún tiempo la palabra tertulia fue sinónimo de academia. Esta última se utilizaba en el barroco con 
el significado concreto de lo que hoy llamaríamos tertulia literaria. La tertulia se vinculaba a la clase media y señalaba durante el siglo XVIII a una reunión casi familiar y casera que exigía cierta especialización en los temas".

Este concepto evolucionó con el tiempo por la llegada de los medios de comunicación, en los que las primeras tertulias tuvieron lugar en los años 40 del siglo XX, concretamente en la radio. En cambio, no sería hasta los años 80 cuando comenzase su proliferación, debido al aperturismo informativo por la llegada de la Democracia que conllevó a la política a convertirse en el foco de atención de la mayoría de los programas de radio (García, 2006: 87-88).

La primera tertulia de la época democrática fue La Trastienda (1984) de la Cadena SER, a la que siguieron La Espuela (1987) de la COPE -desde 2004 en Radio Intereconomía- y La Brújula (1992) de Onda Cero. El mayor crecimiento de este tipo de programas se produjo en la segunda legislatura de Felipe González (PSOE) (Moreno, 2002: 276), de tal manera que tuvieron su máximo esplendor en los años 90.

Con las tertulias políticas se pretendía contribuir a la creación de un foro público en el que se garantizase una reflexión y participación ciudadana libres, siempre que las opiniones emitidas se basasen en la información, en el criterio y en la capacidad argumental (Sánchez, 2005: 141). Esta fórmula fue imitada más tarde por la televisión y en el siglo XXI se convirtieron en un elemento clave de las parrillas de programación de los medios audiovisuales, es el caso del Grupo Intereconomía.

La importancia adquirida por las tertulias ha supuesto que se la haya considerado como "un género periodístico que manifiesta el punto de vista concreto sobre un determinado tema, considerado de especial relevancia en la actualidad, a través de la interpretación y la valoración" (Moreno, 2002). Consiste en un género de opinión y dialógico que es diferente a los debates y a los coloquios, porque "los coloquios siempre buscan un clima de serenidad frente al espectáculo. Las discrepancias, la diversidad de opiniones en los coloquios, no tienen por qué consolidarse en verdaderos enfrentamientos. Por otro lado, las tertulias, además de fomentar un ambiente de camaradería en el que el sosiego es la nota dominante, tienen como participantes habituales a los mismos colaboradores. Ello lleva a que los espectadores puedan lograr una identificación y cercanía, una familiaridad entre el público y el espacio televisivo" (Gutiérrez, 2005).

\section{Características básicas de las tertulias políticas del Grupo Intereconomía}

Para conseguir esta familiaridad, las tertulias tienen unas características que permiten identificarlas: periodicidad fija, participantes habituales, referencia a la actualidad, variedad y alternancia de temas, utilización de la técnica del "back-ground", libertad estructural y organizativa, emisión en directo y discrepancia pero no enfrentamiento radical (Sánchez, 1994: 45-48).

Concretamente, en lo que se refiere a la periodicidad, las tertulias pueden ser diarias y semanales. En este sentido, tanto La Espuela (emitida por Radio Intereconomía) como El Gato al Agua (emitida por Intereconomía TV y Radio Intereconomía) eran diarias (de lunes a viernes), mientras que Más se perdió en Cuba (emitida por Radio Intereconomía e Intereconomía TV) era semanal. Todas eran nocturnas. 
Por otra parte, y en líneas generales, en cuanto a los participantes habituales, también llamados tertulianos o contertulios, suelen ser periodistas, políticos, personajes públicos y profesionales de prestigio, pero con la peculiaridad de que son elegidos por los propios medios dentro de su línea editorial, para que apoyen las ideas y los intereses que defienden (Cebrián, 2001:180-200), por lo que se da una cierta homogeneidad de ideas. Es cierto que para dar imagen de pluralismo suelen seleccionar también a personas con una ideología diferente, pero, a pesar de ello, se aprecia una tendencia a la uniformidad ideológica.

Como dice Moreno (2002) estos contertulios deben tener un profundo conocimiento de la actualidad, capacidad de interpretación y análisis y de expresión clara. El estilo de su lenguaje debe ser ágil, preciso y cuidado que permita un acercamiento a un público amplio.

En este sentido, cabe decir que los tertulianos de estos programas del Grupo Intereconomía eran periodistas -Isabel Durán, Alfonso Rojo, Jaime González, Melchor Miralles, Carmelo Encinas, Ricardo Martin, Carlos Dávila...-, políticos -Alejo VidalQuadras (PP), Cristina Alberdi (ex PSOE), Antonio Miguel Carmona (PSOE), Francisco Granados (PP), Gustavo de Aréstegui (PP), José Manuel García-Margallo (PP), José Ignacio Wert (PP), José Manuel Soria (PP), Miguel Arias Cañete (PP), José Luis Balbás (ex PSOE), Alicia Sánchez-Camacho (PP)...-, economistas -Juan Iranzo, Luis de Guindos...-, empresarios -Mario Conde...- y abogados -Joaquín Moeckel, Javier Nart, Pablo Castellano...-. Varios de ellos fueron nombrados ministros por Mariano Rajoy (PP).

También es importante señalar que la mayoría de los tertulianos participaban indistintamente en los programas estudiados, como Isabel Durán que colaboraba en $E l$ Gato al Agua y además era directora de La Espuela. Esto es un indicio de la simbiosis entre la radio y televisión.

Por otro lado, con relación a los temas tratados, giraban en torno a la política. De esta manera, en La Espuela, la política nacional suponía el 15.22\%, la política económica española un $10,87 \%$, la política financiera española un $10,87 \%$, las relaciones diplomáticas un 5,43\%, el independentismo un 5,43\%, las elecciones autonómicas un $5,43 \%$, la política educativa un $4,35 \%$ y la política antiterrorista un $3,26 \%$, etc. Por consiguiente, la política es tratada desde diferentes puntos de vista como se puede constatar en el gráfico que se incluye a continuación:

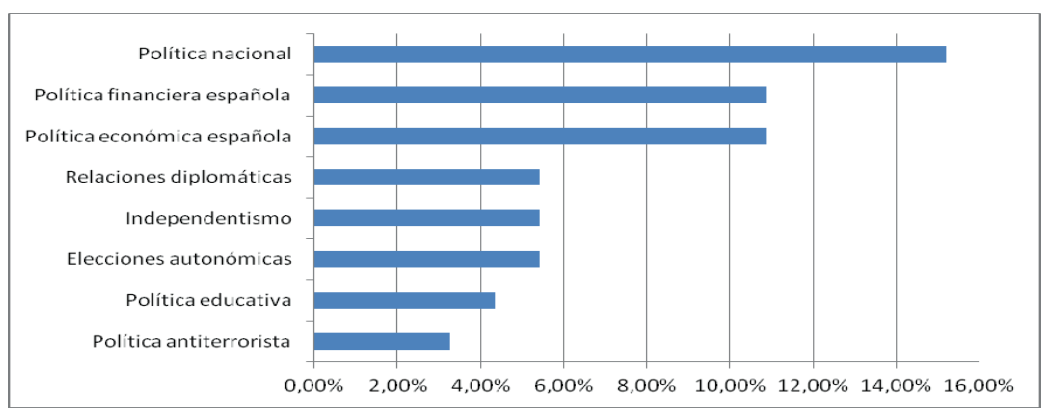

Gráfico 1: Porcentaje de temas tratados en La Espuela. Fuente: Elaboración propia 
Del mismo modo, en El Gato al Agua, la política nacional también ocupaba el primer puesto con un $17,65 \%$, la política económica española el segundo con un $15,69 \%$, la política financiera el tercero con un $10,78 \%$ y, así sucesivamente, como se puede ver en este gráfico:

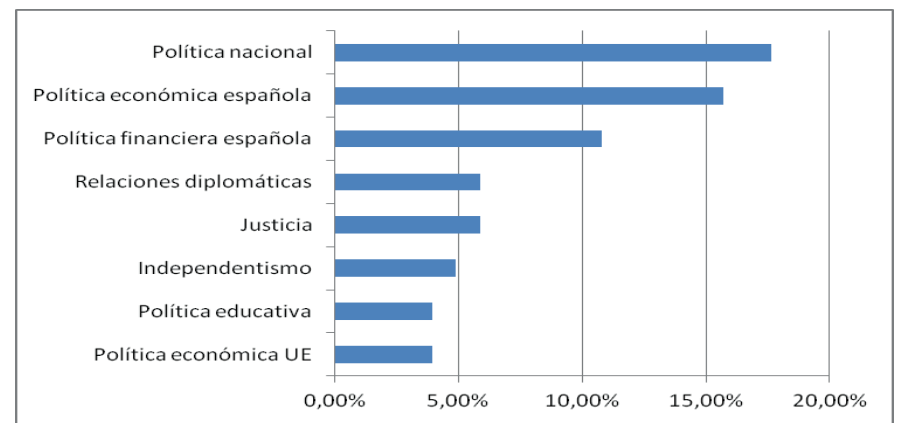

Gráfico 2: Porcentaje de temas tratados en El Gato al Agua. Fuente: Elaboración propia

En el tercer programa analizado, Más se perdió en Cuba, los resultados obtenidos fueron: política económica española un $18,75 \%$, finanzas un $9,38 \%$, política nacional un $9,38 \%$, política antiterrorista un $6,25 \%$, etc.

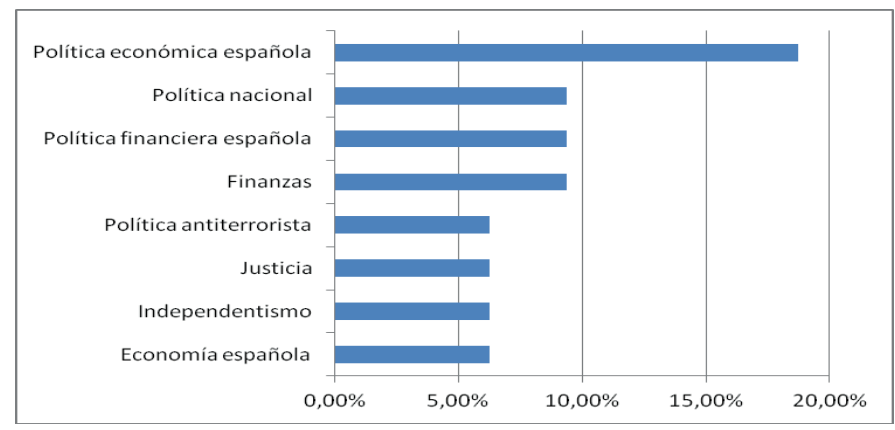

Gráfico 3: Porcentaje de temas tratados en Más se perdió en Cuba.

Fuente: Elaboración propia

Por tanto, si se tiene en cuenta que las tertulias se pueden clasificar en monotemáticas o pluritemáticas, las tres estudiadas serían pluritemáticas, aunque el eje fuese la política. Otra característica que diferencia a las tertulias es su estructura y que viene determinada por las acciones comunicativas.

\section{La aplicación de los géneros informativos e interpretativos en las tertulias po- líticas de Intereconomía}

Como dice Casals (2005: 430-433) "el periodismo ha creado un tipo de retórica que desarrolla continuamente dos acciones comunicativas: narrativa y opinión". La primera de ellas relata los hechos de la actualidad y asuntos relacionados de la realidad social, mientras que la segunda explica y juzga hechos de la actualidad, así como los asuntos de la realidad social. 
Estas acciones se van a traducir en lo que Díaz (2006: 219-222) denominó estilos narrativos, de los que dijo que eran "el enfoque e intencionalidad con que se formaliza la realidad en imágenes, sonidos y palabras. Existen estilos empresariales o institucionales y estilos personales. Los primeros definen la orientación editorial de la empresa de comunicación a través de una serie de formalizaciones, como es la imagen corporativa, los principios editoriales, los libros de estilo, etcétera. El segundo es el propio de cada profesional".

A su vez, según el mismo autor, los estilos empresariales se pueden clasificar en:

- Informativo: Requiere un tono neutro por parte del periodista y consiste en interpretar la realidad desde los propios hechos sin juzgarla ni dar opiniones sobre ella.

- Interpretativo: Se trata de contar al público lo que ha sucedido, pero desde un punto de vista personal, porque se realiza mediante la selección que hace el periodista de los recursos informativos. Se utilizará la tercera persona o el narrador hablará desde la postura de testigo directo. Tampoco se juzgará.

- Estilo opinativo: Consiste en interpretar los hechos desde unas ideas o valores, por lo que la aproximación a la realidad se realiza desde la valoración.

- Estilo artístico: Se trata de reinterpretar la realidad de forma creativa y es característico de los docudramas.

Todos estos estilos son el origen de los géneros periodísticos que "son macroestructuras discursivas útiles (para el periodista y para el receptor) en muchos aspectos: orden, tiempo, espacio, ética, continuidad" (Casals, 2005: 430-433). De ahí que se pueda hablar de géneros informativos -noticia e informe-, interpretativo -crónica, reportaje y documental-, opinativos -entrevista, crítica, tertulia y debate-, y artísticos docudrama y obra abierta-.

Desde el punto de vista de los medios audiovisuales, el género es "una modalidad de creación del relato, ya sea este literario, cinematográfico, teatral, periodístico, radiofónico, etcétera" (Merayo, 2002: 83). Sin embargo, como los medios audiovisuales se pueden clasificar en dos tipos, radiofónicos y televisivos, se pueden establecer más definiciones.

\subsection{Géneros audiovisuales radiofónicos}

Del mismo modo, y de acuerdo con el profesor Merayo, el género radiofónico es “cada uno de los modos de organizar el mensaje radiofónico, de manera que la estructura resultante pueda ser reconocida como perteneciente a una modalidad característica de creación y construcción del relato radiofónico".

Por otra parte, los géneros de la radio, además de catalogarse según la clasificación mencionada en párrafos anteriores, por ser un medio en el que se suele combinar la información de los hechos con la valoración de los mismos, también se pueden tipificar en géneros de monólogo y géneros dialógicos. En este sentido, Merayo explica que los primeros son "la presentación de cualquier contenido realizada por uno o varios locutores que intencionalmente no dialogan entre sí ni con terceras personas", mientras que los segundos son estructuras narrativas configuradas en función de varios hablantes que intervienen en un discurso. 
Además, si se tiene en cuenta la catalogación clásica, los géneros informativos son la noticia y el informe; sin embargo, ¿qué se entiende por noticia y por informe en la radio? "La noticia es la narración de los elementos básicos del hecho y, si es necesario, su breve explicación, utilizando los documentos sonoros más significativos e imprescindibles" y el informe "es la ampliación de datos significativos, el análisis de las causas y consecuencias, la contextualización o explicación de temas técnicos" (Merayo, 2002: 87-88). Ambos son, a su vez, géneros de monólogo.

En lo que se refiere a los géneros interpretativos, la crónica radiofónica "es una información interpretativa y valorativa de hechos noticiosos, donde se narra algo a la vez que se juzga lo narrado" (Merayo, 2002: 89).

Según Herrera (2007: 1) "el reportaje es un modelo de representación de la realidad que, a partir del monólogo radiofónico, persigue narrar y describir hechos y acciones de interés para el oyente, proporcionándole un contexto de interpretación amplio en los contenidos y un uso de fuentes variado y creativo".

Otros géneros son los interpretativos -entrevista, artículo, editorial, crítica, tertulia y debate-.

La entrevista radiofónica consiste en la obtención de información mediante el diálogo, por lo que también es un género dialógico, mientras que "basado en el monólogo, el artículo radiofónico pretende, igual que el editorial, analizar, interpretar, valorar y enjuiciar los hechos, pero desde una perspectiva individual y no institucional" (Merayo, 2002:90).

En lo que se refiere a la crítica se trata de una estructura que consta de información, valoración y recomendaciones (Cebrián, 2007:123-148). El mismo autor define tertulia como una conversación o discusión informal de periodistas y expertos sobre la actualidad. En cambio, considera debate como una confrontación de ideas de dos o más personas bien mediadas por el periodista, o bien por un diálogo entre ellas.

\subsection{Géneros audiovisuales televisivos}

En la misma línea de argumentación, si se tienen en cuenta la teoría sobre los estilos narrativos del profesor Díaz (2006: 219-222) y las características de la televisión como medio de comunicación, el género televisivo se podría definir como aquel discurso estructurado en función del objetivo de acto comunicativo, el cual puede ser informar, interpretar o juzgar.

Igual que en los medios radiofónicos, los géneros televisivos se pueden clasificar en informativos -noticia -, interpretativos -crónica, reportaje y documental-, opinativos -entrevista, crítica, comentario, tertulia y debate- y artísticos -docudrama-

En este caso, la noticia se define como una estructura informativa cuya finalidad primordial es relatar hechos actuales, siendo las imágenes el recurso fundamental. Según el profesor Cebrián (1992: 120-247), se trata de "la perfecta combinación de imágenes y sonidos para dar un relato único y no diversificado o incluso contrario", ya que su lenguaje debe combinar "coherentemente y con unidad narrativa las imágenes y sonidos".

En cuanto a los géneros interpretativos, la crónica "consiste en la información sobre unos hechos ocurridos durante un período de tiempo desde el lugar mismo, o próximo 
a donde han ocurrido, por el informador que los ha vivido como protagonista, testigo o investigador y que conoce las circunstancias que lo rodean. Se refiere a un hecho o conjunto de hechos con cierta vinculación entre sí por el tema, personas implicadas y lugar donde se produce" (Cebrián, 1992, 88-112).

En lo que respecta al reportaje televisivo "es una profundización que lleva consigo un análisis y una interpretación en la presentación y estudio de una cuestión que se aborda" (Moreno, 2003: 269-280).

Otro género interpretativo es el documental. Se trata de una estructura exclusiva de la televisión que consiste en reflejar la realidad con fines informativos.

Por otro lado, con relación a los géneros opinativos, la entrevista consiste en un diálogo en el que uno o varios periodistas preguntan a un personaje sobre sus ideas (Moreno, 2003: 269-280). En cambio, la crítica es un análisis basado en argumentos sólidos sobre un tema literario, artístico o deportivo y el comentario es una opinión, normalmente argumentada, sobre un hecho.

En cuanto a la tertulia es un intercambio de opiniones entre varios participantes o tertulianos habituales sobre un tema previamente fijado y durante un tiempo determinado. Suele haber un moderador que se ocupa de introducir el tema y del desarrollo de la misma.

Sin embargo, el debate consiste en examinar un hecho (social, político, científico, educativo...) entre dos o más personas que tienen distintas opiniones. El objetivo es alcanzar conclusiones o decisiones en un tema controvertido o en una situación conflictiva que satisfagan a la mayoría de los participantes.

Finalmente, con relación a los géneros artísticos, el docudrama es un documental con tintes dramáticos en el que se puede utilizar la creatividad desde el punto de vista de la producción y la realización.

\subsection{Los géneros en las tertulias políticas del Grupo Intereconomía}

Por todo lo expuesto, y sobre todo por dicho sobre la tertulia, de la que hemos dicho que se trata de un género dialógico y opinativo, cabría esperar un formato basado en un grupo de personas que dialogan sobre unos temas de actualidad; sin embargo, esto no era así en el Grupo Intereconomía por diversos motivos.

En primer lugar, en La Espuela, aunque el género por excelencia era el comentario de las informaciones con un $97,87 \%$, hubo ocasiones en las que también se incluyeron noticias sobre las que no se opinó como se puede apreciar en el siguiente gráfico:

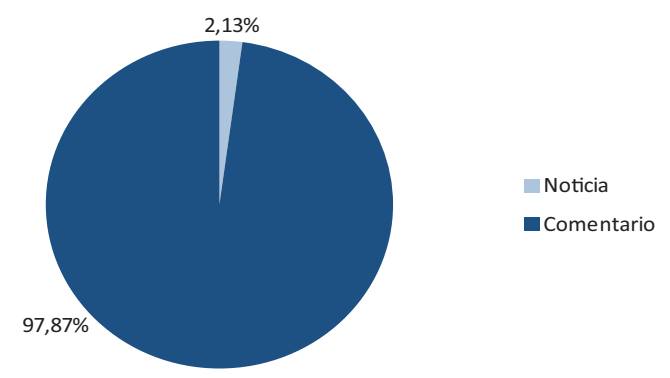

Gráfico 4: Porcentaje de géneros utilizados en La Espuela. Fuente: Elaboración propia 
Las cifras de este gráfico ponen de manifiesto que esta tertulia radiofónica se ajustaba, prácticamente, al formato clásico de la teoría general.

La otra tertulia estudiada fue El Gato al Agua, en la que era habitual encontrar una combinación de diferentes géneros. Así, en el $76 \%$ de las ocasiones se combinó la noticia con el comentario. Esto eso, se daba una noticia con el formato propio del medio televisivo y a continuación se comentaba esta. Igualmente, y con el mismo orden, en el 9\% de los asuntos tratados, se ofrecía un reportaje e inmediatamente se hablaba de su contenido.

El cometario estricto se utilizó en un $13 \%$ de los temas, mientras que la entrevista y la noticia solo se empleó un $1 \%$ cada una. Estos datos se pueden comprobar en el siguiente gráfico:

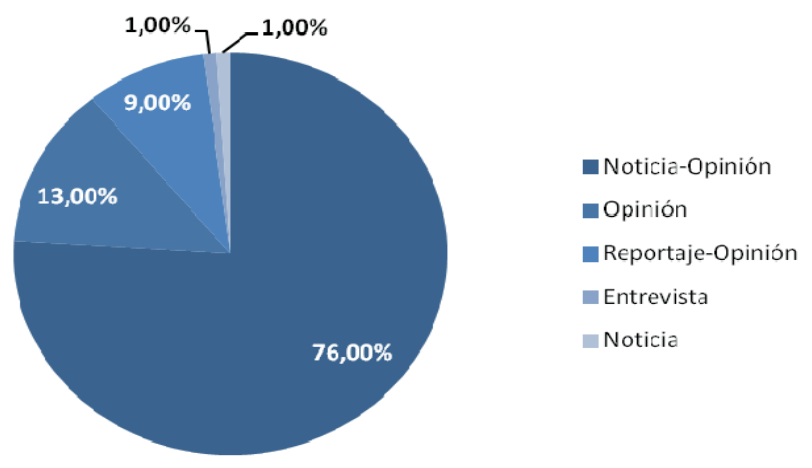

Gráfico 5: Porcentaje de géneros utilizados en El Gato al Agua. Fuente: Elaboración propia

En cuanto a Más se perdió en Cuba, el 48,48\% fueron comentarios estrictos, el $45.45 \%$ reportajes comentados, el 3,03\% entrevistas y el 3,03\% noticias comentadas como se puede ver a continuación:

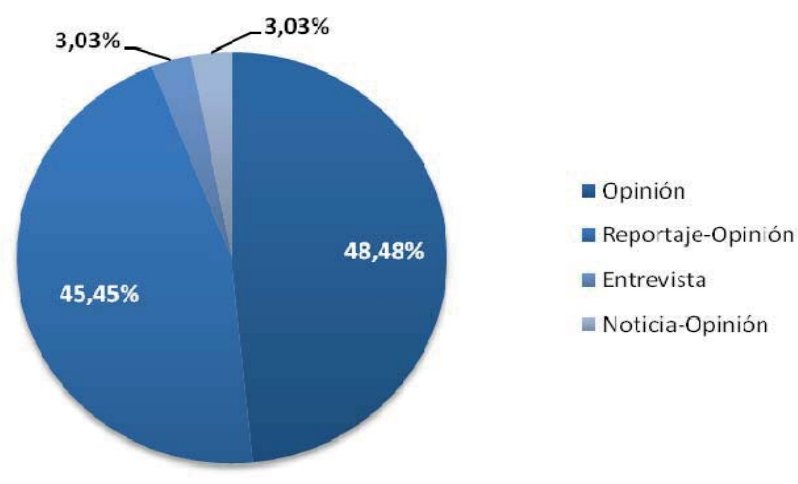

Gráfico 6: Porcentaje de géneros utilizados en Más se perdió en Cuba. Fuente: Elaboración propia 


\section{Conclusiones}

Los porcentajes obtenidos al estudiar los asuntos tratados en las tertulias analizadas del Grupo Intereconomía nos permite afirmar que se puede hablar de pluritemáticas, aunque el eje sea un mismo tema, y como puede ser la política.

Igualmente, en cuanto la aplicación de los géneros en La Espuela, El Gato al Agua y Más se perdió en Cuba, los resultados nos llevan a concluir que estas tertulias se caracterizaban por la combinación del estilo informativo, el estilo interpretativo y el estilo opinativo y, por consiguiente, que no se puede considerar la tertulia como un género de opinión, sino como un formato televisivo en el que prima este.

Por tanto, la combinación de los géneros informativos con los géneros opinativos, ya no es un rasgo propio de los programas informativos, sino que también tiene lugar en programas que, tradicionalmente, se han considerado "de opinión".

\section{Referencias bibliográficas}

CASALS CARRO, María Jesús (2005): Periodismo y sentido de la realidad. Teoría y análisis de la narrativa periodística. Madrid, Fragua.

CEBRIÁN HERREROS, Mariano (2004): La información en televisión. Obsesión mercantil y política. Barcelona, Gedisa.

CEBRIÁN HERREROS, Mariano (2001): La radio en la convergencia multimedia. Barcelona, Gedisa.

CEBRIÁN HERREROS, Mariano (1992): Géneros informativos audiovisuales: radio, televisión, periodismo gráfico, cine, video. Madrid, Ciencia 3 Distribución.

DÍAZ ARIAS, Rafael (2006): Periodismo en Televisión. Entre el espectáculo y el testimonio de la realidad. Barcelona, Bosch Comunicación.

GARCÍA AVILÉS, José Alberto (2006): “Convergencia y polivalencia periodística en televisiones europeas y norteamericanas". Global Media Journal, vol. 3, núm. 6, pp. 28-43.

GUTIÉRREZ LOZANO, Juan Francisco (2005): "La presencia del debate en televisión y su utilidad en la calidad de las programaciones". Comunicar: Revista científica iberoamericana de comunicación y educación, 25 (2). Huelva, CD-Rom. En: http://www.revistacomunicar.com/verpdf.php?numero=25\&articulo=25-2005-143

HERRERA DAMAS, Susana (2007): "La estructura del reportaje en radio". Área Abierta, 17, pp. 1-22.

MATEOS-PÉREZ, Javier (2009): "La información como espectáculo en el nacimiento de la televisión privada española (1990-1994)". Estudios sobre el Mensaje Periodístico, vol. 15, pp. 315-334. Madrid, Servicio de Publicaciones de la Editorial Complutense.

MERAYO PÉREZ, Arturo (2002): "La construcción del relato informativo radiofónico”. En MARTÍNEZ-COSTA, María Pilar (coord.): Información radiofónica. Cómo contar las noticias en la radio hoy. Barcelona, Ariel Comunicación, pp. 5983. 
MORENO ESPINOSA, Pastora (2003): "El periodismo informativo en televisión". Estudios sobre el Mensaje Periodístico, vol. 9, pp. 269-280. Madrid, Servicio de Publicaciones de la Editorial Complutense.

MORENO ESPINOSA, Pastora (2002): "La tertulia radiofónica, foro para el siglo XXI". Estudios sobre el Mensaje Periodístico, vol. 8, pp. 275-291. Madrid, Servicio de Publicaciones de la Editorial Complutense.

SÁNCHEZ, Chelo (2005): "Las tertulias políticas de la radio española. Un ejercicio de comunicación política mejorable". Comunicación y pluralismo, $\mathrm{n}^{\circ} 0$, pp. 141152.

SANTAMARÍA SUÁREZ, Luisa \& CASALS CARRO, María Jesús (2000): La opinión periodística. Argumentos y géneros para la persuasión. Madrid: Fragua. 